\title{
Tick Mistaken as a Mole
}

\author{
Neel P1, Ripudaman $\mathrm{A}^{2 *}$, Satish $\mathrm{S}^{2}$ and Nitin M Nagarkar ${ }^{2}$ \\ ${ }^{1}$ Department of Dermatology, Venereology \& Leprology, All India Institute of Medical \\ Sciences, India \\ ${ }^{2}$ Department of ENT \& HNS, All India Institute of Medical Sciences, India

\section{Case Report \\ Volume 4 Issue 2} \\ Received Date: September 21, 2019 \\ Published Date: October 17, 2019 \\ DOI: $10.23880 /$ ooaj-16000186
}

*Corresponding author: Ripudaman Arora, Department of ENT \& HNS, All India Institute of Medical Sciences, Chhattisgarh, India, Tel: 91-8518881782; Email: ripuarora@aiimsraipur.edu.in

\section{Abstract}

Ticks are blood sucking ectoparasites of vertebrates. They are vectors for the transmission of a number of viral, rickettisal and bacterial diseases. Humans become accidental hosts when they enter in tick infested area. Tick bite presents with varied cutaneous manifestations. Sometimes the attached tick is mistaken for skin lesions such as traumatized, papillomatousnaevus, melanoma or mole. We here presented a case of a female who suspected tick as a mole. The tick was carefully removed. If clinician is aware of ticks, diagnosis can be easily made by close inspection of tick. This case report suggests that tick bite should be kept in differential diagnosis of sudden onset pigmented skin lesion.

\section{Introduction}

Ticks are blood sucking ectoparasites of vertebrates. They are vectors for the transmission of a number of viral, rickettisal and bacterial diseases. Humans become accidental hosts when they enter in tick infested area. For obtaining blood meal tick uses its toothed chelicerae to cut into epidermis. It thrust its hypostome into the opening and gradually penetrates dermis and attaches to skin [1]. Sometimes the attached tick is mistaken for skin lesions such as traumatized, papillomatousnaevus, melanoma or mole [2-4]. We here presented a case of a female who suspected tick as a mole.

\section{Case Report}

A 20 year old female presented in the dermatology outpatient department with history of sudden onset of mole behind left ear since 2 days. There was history of itching. She gave a history of recent visit to a forest area for picnic. On examination a black colored papule was seen in left retro auricular area. On close inspection, a tick anchoring the skin was appreciated (Figure 1). A drop of surgical spirit was put over the tick, and then it was gently gripped with fine forceps close to skin and removed by gentle traction (Figure 2). A small erythematous bite mark was seen after removal of the tick. Patient was given doxycycline prophylactically. Patient was followed up to 2 weeks and she was asymptomatic.

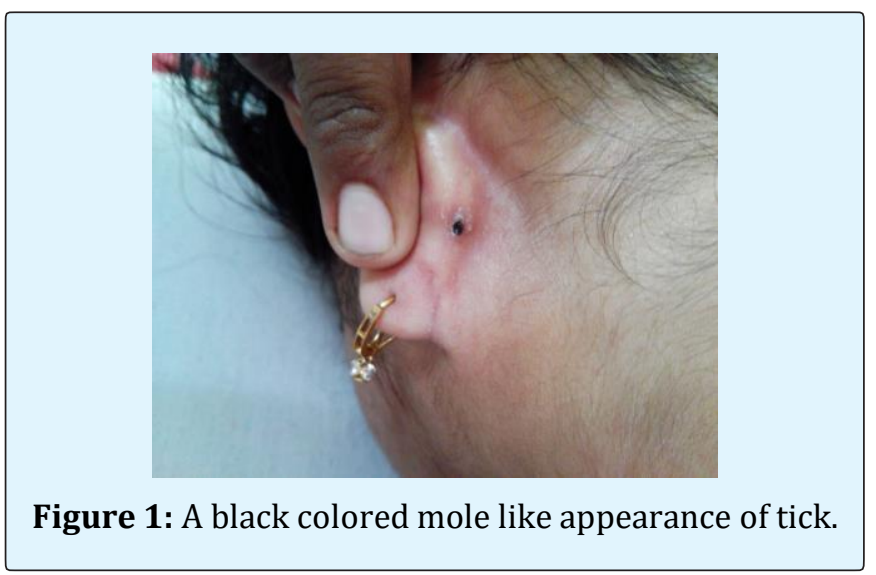




\section{Otolaryngology Open Access Journal}

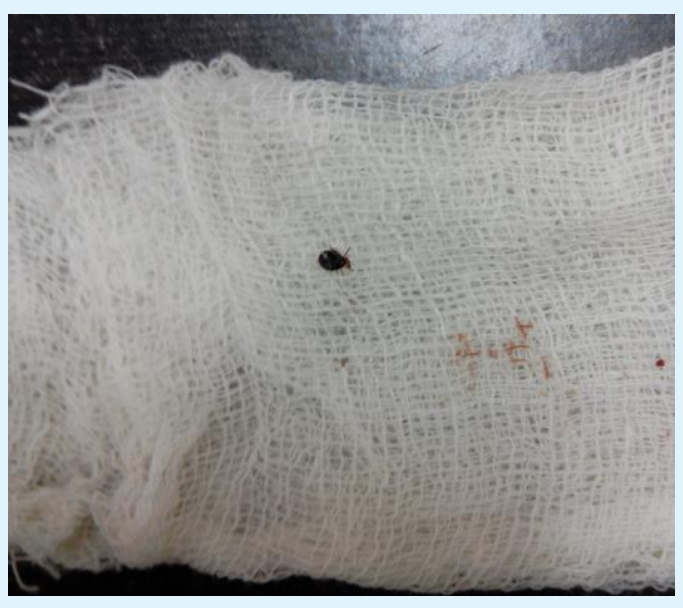

Figure 2: Tick after removal.

\section{Discussion}

Tick bite presents with varied cutaneous manifestations, which depends on tick species, feeding duration, previous exposure to tick bite and individual sensitivity [5]. Acute lesions include erythematous macules, papules, nodules, tissue necrosis or ulcers at the site of bite mark. Chronic lesions include tick bite granuloma, auto-eczematization, alopecia and secondary infection [5]. The chronic lesions may be due to persistence of tick material in the dermis.

Sometimes attached tick can be mistaken for some dermatoses by the patient or the clinician. Novick, et al. described a case report of 54 year-old male who presented with painful skin lesion on his left inner thigh [2]. The clinician suspected the lesion as traumatized, papillomatous nevus. Histopathology of the lesion showed body parts of tick. If clinician is aware of ticks, diagnosis can be easily made by close inspection of tick. Dermoscopy has also helped in making the diagnosis, especially in larval and nymphal forms of tick bites [6,7].

Various methods has been described for tick removal. Tick should be removed carefully by the clinician so that the body parts should not be left behind. Tick can be removed after application of iodine, chloroform, ether, kerosene, petrol, clear nail varnish and lidocaine [1]. It should be gently gripped with fine forceps or tweezers as close to the skin as possible followed by gentle traction [1]. Tick can also be removed by surgical approach like punch or elliptical excision [8]. This is more invasive but it confirms complete removal of tick.
It is still debatable whether to give or not prophylactic treatment after tick bite. Patient should be informed about signs and symptoms of tick bite related diseases. Tick bites can be prevented by avoidance of tick infested areas and use of tick repellents [5]. Tick bite related diseases can be prevented by rapid removal of tick or giving prophylactic treatment or rapid treatment if symptoms of disease appear [5].

\section{Conclusion}

Tick bite should be kept in differential diagnosis of sudden onset pigmented skin lesion. It should be removed carefully by the clinician so that the body parts should not be left behind. Patient should be informed about signs and symptoms of tick bite related diseases.

\section{References}

1. Burns DA (2010) Diseases caused by arthropods and other noxious animals. In: Burns $\mathrm{T}$, et al. (Eds.), Rook's Textbook of Dermatology, $8^{\text {th }}$ (Edn.), Oxford: Wiley-Blackwell.

2. Novick NL, Reitano M (1986) Tick infestation simulating a traumatized papillomatous nevus. Am J Med 81(4): 721-722.

3. Halpern SM, Munro DD (1994) Tickborne melanoma?. BMJ 309(6970): 1693.

4. Kallini JR, Khachemoune A (2017) Ticks and tick bites presenting as "Funny Moles": A review of different presentations and a focus on tick-borne diseases. J Clin Aesthet Dermatol 10(3): 46-50.

5. Monsel G, Delaunay, Chosidow (2016) Arthropods In: Griffiths C, et al. (Eds.), Rook's Textbook of Dermatology, $9^{\text {th }}$ (Edn.), Oxford: Wiley-Blackwell.

6. Oiso N, Kawara S, Yano Y, Kawada A (2010) Diagnostic effectiveness of dermoscopy for tick bite. J Eur Acad Dermatol Venereol 24(2): 231-232.

7. Oiso N, Nakano A, Yano Y, Kawada A (2010) The diagnostic usefulness of dermoscopy for identifying six-legged larval ticks. Ticks Tick Borne Dis 1(4): 197198.

8. Moehrle M, Rassner G (2002) How to remove ticks?. Dermatology 204: 303-304. 